\title{
Making the best use of all resources: developing a health promotion intervention in rural Nepal
}

\author{
E v Teijlingen ${ }^{1-2}$, P Simkhada ${ }^{2-3}$, J Stephens ${ }^{4}$, B Simkhada ${ }^{5}$, SW Rogers ${ }^{6}$, S Sharma ${ }^{7}$
}

${ }^{1}$ Professor in School of Health \& Social Care, Bournemouth University, UK

${ }^{2}$ Visiting Professor at Manmohan Memorial Institute of Health Sciences, Tribhuvan University, Kathmandu, Nepal, ${ }^{3}$ Senior Lecturer, ScHARR, University of Sheffield, UK, ${ }^{4}$ Director- Green Tara Trust (UK), ${ }^{5}$ Director- Green Tara Nepal, ${ }^{6} \mathrm{PhD}$ student- Institute of Health Science, University of Aberdeen, Scotland, ${ }^{7} \mathrm{PhD}$ student- School of Health \& Social Care, Bournemouth University, UK

\begin{abstract}
This paper describes and analysis the needs assessment, planning, structure and development of a community-based health promotion intervention in rural Nepal. This intervention, funded by a UK charity called Green Tara Trust differs from many interventions in industrialised countries where a new health promotion intervention is introduced in the context of a complex pre-existing mixture of health education and health promotion interventions. The health promotion intervention is fairly unique in Nepal, as it is: (a) multidisciplinary; (b) theorybased; and (c) evidence-based. The intervention started with a community-based needs assessment and a consultation around the first design by funders and academics in conjunction with local policy makers and participatory activity. Where possible, Green Tara incorporated the diverse/changing needs of the local communities and made best use of the existing resources whether these were delivered by the government or by non-governmental organisations (NGOs). Helping to improve the local maternity service provision and advocate its uptake makes it much more likely that the intervention becomes sustainable compared to the introduction of an expensive external intervention which is new to the community.
\end{abstract}

Keywords: health promotion, maternal health, developing countries, Nepal,

\section{Background}

Health promotion represents a comprehensive social and political process. It embraces actions directed at strengthening the skills and capabilities of individuals and also changing social, environmental and economic conditions so as to alleviate their impact on public and individual health. ${ }^{1}$

Improving maternal and child health are priorities in Nepal. Research suggests that the maternal mortality ratio (MMR) is decreasing although it is still fairly

Address for correspondence

Dr Edwin van Teijlingen

Professor in School of Health \& Social Care, Bournemouth University, UK

Visiting Professor at Manmohan Memorial Institute of Health Sciences, Tribhuvan University, Kathmandu, Nepal

Email: vanteijlingen@bournemouth.ac.uk high in Nepal. The MMR was estimated to be 281 deaths per 100,000 live births ${ }^{2}$, and in a recent study in eight districts reported $229 / 100,000^{3}$. The good news is that Nepal is likely going to achieve its target for Millennium Development Goal (MDG) 5 of reducing the maternal mortality ratio by three quarters between 1990 and $2015^{4}$, a target set by the Ministry of Health at $250 / 100,000 .{ }^{5}$ One key strategy in achieving this improvement is to increase the uptake of antenatal care (ANC).

ANC has both a public health screening and a health promotion intervention function. It provides an opportunity to inform pregnant women about the danger signs and symptoms for which (immediate) help should be sought from midwife or doctor. ANC also provides health information and services which 
help improve women's own health and that of their babies. ${ }^{6}$ ANC does not manage to screen out all potential complications hence there is a need for emergency obstetric care with a skilled birth attendant. Coverage and uptake of ANC has historically been low in rural Nepal and maternal mortality rates relatively high. ${ }^{7,8}$ Simkhada and colleagues in their review provided a range of different reasons for the low uptake of ANC in Nepal..$^{9}$ One of the development aid interventions in many developing countries like Nepal has centred on improving existing health services such as ANC.

\section{Development aid and Nepal}

Third world development (henceforth 'aid') is a contested field at all levels. At the global level of political theory some argue that developing countries are poor because they are in a position of exploitation by first world countries, and that development aid does nothing but keep countries and people in this position of dependency. ${ }^{10}$ Others have argued that aid, through the development of infrastructure and human capacity building can help developing countries to compete with developed countries on the world market. At a community level, aid can create dependency; many argue that many development projects collapse after the donor money runs out. Few authors have reflected on the hidden costs of abandoning or withdrawing development aid, which can include: "staff demoralized, people disillusioned, government discredited, 'money down the drain', benefits for the poor foregone, and opportunities lost ...". " Others have highlighted that aid which is sensitive to people's needs and which builds on locally available resources is more likely to be sustainable. ${ }^{12,13}$ Nepal has received billions in development aid since 1950, in 2003-04 alone the total foreign aid received was NRs 189.12 billion. ${ }^{14}$ One would argue that had this aid been put to encourage communities to develop their own interventions that were self-sustaining in the long term from guidance by donor countries; Nepal's development in socio-economic and health outcomes would be better.

\section{The Green Tara Health Promotion intervention programme}

There has been little research specifically focused on the health-promotion design in Nepal; there is clearly a health promotion research gap. ${ }^{15}$ Therefore, we searched the literature on health promotion in the field of maternity care developing countries prior to commencement. Based on appropriate needs assessment and the engagement of both (potential) users and the wider local community the intervention aimed to increase the uptake of ANC. Green Tara realised that countries of the South are dependent on what aid dictates by first world countries, a situation which requires political change. At the same time, Green Tara is aware that such change is not likely to occur in the near future, hence the immediate aim to improve the lives of people within the current global structure. Green Tara thus concentrated on developing a community-based health promotion programme which aims to increase the uptake of ANC and skilled attendance at delivery and postnatal care (PNC) in rural Nepal; both recognised measures in targeting the reduction of maternal mortality. ${ }^{16}$

It is important to remember that about $85 \%$ of Nepal is rural, with people sometimes being 3 hours walk or more away from their nearest health facility; one aim of this programme was to understand why pregnant women do not access existing services to help improve this behaviour, as well as strengthening existing service provision. Dickerson and colleagues report a similar type of community intervention in Tibet; using low-cost resources to work in the community, and deliver maternal-newborn health interventions to those at risk of unskilled attendant during delivery. ${ }^{17}$

The intervention focused on localities, two rural VDCs (Village Development Committee areas), 20 $\mathrm{km}$ south of the capital Kathmandu. These were typical VDCs in Kathmandu Valley, which are relatively underdeveloped, but slightly more developed than the average VDC in rural Nepal. The total population of the two VDCs was just under $9,000 .^{18,19}$

Most births and newborn deaths occur at home in Nepal as in most developing countries), therefore it is important to consider behavioural change interventions aimed at improving care at home and care-seeking behaviour in any strategy to reduce mortality. ${ }^{20}$ The Government of Nepal's strategy has been to increase the number of women delivering in health facilities but in rural areas this may be unrealistic. Few studies have evaluated strategies 
and act pragmatically and look at immediate problems and medium-term organisational solutions to improve health care delivery and still use a theoretical underpinning.

Green Tara aimed to make realistic improvements which are sustainable and research-based. Therefore, the starting point was a study of the community, partly to establish the perceived need and partly to ensure any intervention we designed and implemented was culturally and socially acceptable to the community.

The framework put forward by the Medical Research Council (MRC) for developing and evaluation of complex interventions includes four key interacting stages that are often not linear or cyclical. ${ }^{25}$ The stages suggested by the MRC include:

- Development (identifying the evidence, developing theory, and modelling processes);

- Feasibility/Piloting (testing procedures, estimating recruitment, retention, and sample size);

- Evaluation (assessing effectiveness, change process, and cost-effectiveness);

- Implementation (dissemination, surveillance, monitoring, long-term follow up).

\section{Implementation of the intervention}

Data for Green Tara Nepal's 2011 annual report suggests that the health-promotion intervention had included the involvement and mobilisation of local community, the participation of local Green Tara staff in nine mass health education events on days of religious festivals. The ANC health promotion intervention had been implemented in 40 groups (reaching over 1100 people) and visited 134 households to support women most in need. Improve and expand existing health system of subhealth posts and Mother-Child Health Workers (MCHWs) and Female Health Volunteers (FHVs):

- Training Traditional healers $(\mathrm{n}=11)$

- Health communication training to local health workers

- Training hospital staff (neonatal update).

- Provision of stretchers to three health posts.

- Mobile clinics four visits per month to outlying areas of the community

The incentive of giving a baby blanket to all women who complete four ANC visits. Moreover safe delivery kits were made available at subsidised price and sold through women's groups.
- Establish and support women's groups in the community, plus a few men's and mixed groups

- Mobile phones and phone credit for women's group to enable communication between the group, staff and health facilities

\section{The process}

- Research-based need for intervention and control group;

- Design before and after study;

- Needs assessment (in stages) with the local community;

- Applied for ethical approval from Nepal Health Research Council.

- Green Tara funding and project management.

- University of Aberdeen, the University of Sheffield and Bournemouth University input in kind in terms of staff time for training.

- Student projects (M.Sc \& PhD \& MBChB) which provided quality in-depth information as part of their degrees.

- Locally employed Green Tara Nepal staff.

- Local women and men committing to groups participation.

\section{Table 2: The resources}

- Green Tara funding and project management.

- University of Aberdeen, the University of Sheffield and Bournemouth University input in kind in terms of staff time for training.

- Student projects (M.Sc \& PhD \& MBChB) which provided quality in-depth information as part of their degrees.

- Locally employed Green Tara Nepal staff.

- Local women and men committing to groups participation.

In order to make the research financially feasible the researchers on the team incorporated a number of student projects (Table 2). Thus the intervention design and roll-out included student projects in the target community, where some have been published in international journals, and included studies on postnatal care, ${ }^{26}$ birth $^{27}$; antenatal care ${ }^{28,29}$; issues around translation ${ }^{30}$, and the role of mothers-in-law in decision-making around maternity care issues for their daughters-in-law. ${ }^{31}$

On-going student projects related to the evaluation of the Green Tara intervention include student work 
from collaborating UK universities, for example, a qualitative research project by a medical student from the University of Aberdeen, a Ph.D. project based at the University of Aberdeen, a MPH project based at the University of Sheffield and a Ph.D. project based at Bournemouth University. Table (2) lists range of resources needed to make the project work.

\section{What are the lessons learnt?}

Nepal has its share of the usual developing country issues. None of the above would have made any impact without local women's (and some men's) involvement in making the 40 groups a success. Helping to improve the local maternity service provision and advocating its uptake makes it much more likely that the intervention becomes embedded and hence sustainable compared to the introduction of an expensive intervention, which is new to the local community. Development aid in the form of community-based culturally sensitive health promotion interventions is possible, but their development is time consuming. ${ }^{32}$

In Nepal, the Ministry of Health is interested in using research to improve the health promotion curricula. There are three different levels of evaluation, which can be used to assess the effectiveness of a health promotion programme:

$>$ Process evaluation

$>$ Impact evaluation

$>$ Outcome evaluation

These must be done in a logical order - the shortterm effects of the health promotion programme must be assessed before any long-term benefits can be measured. Planning for evaluation is an essential part of the initial health promotion programme planning process. ${ }^{33}$

Our research study employs a mixed-methods design in both an intervention and control community. The methods process was chosen giving consideration to the sample group and the data outcome required to meet the aims and objectives of the study in a rigorous approach to evaluate the effectiveness of the health promotion intervention.

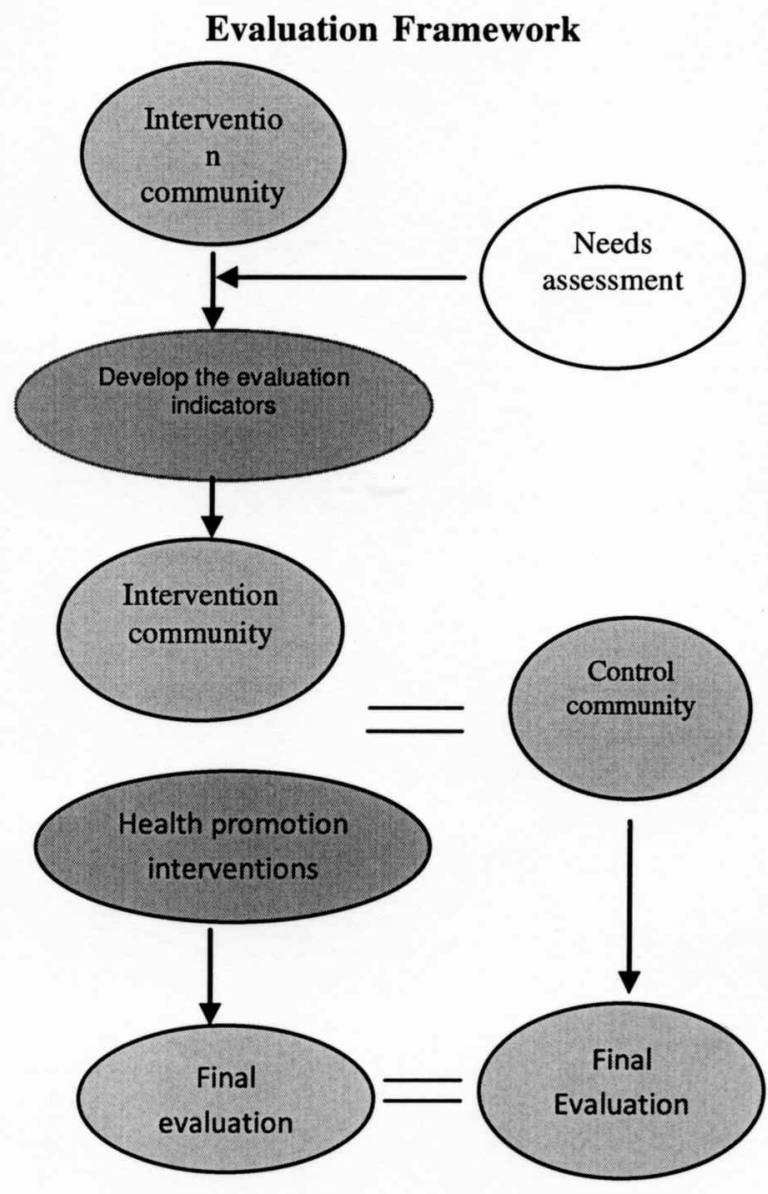

\section{Conclusion}

It is possible to design and implement an evidencebased community maternity care improvement intervention with minimal financial resources, but it does need the practical and academic experience and expertise to bring it altogether. We demonstrated that individual small-scale student research projects can bring together valuable information about the targeted community. These student projects needs skilful coordination as well as academic supervision to ensure that collectively these projects have a synergetic effect. Our intervention is evidencebased, and to ensure it is culturally appropriate and acceptable to the local population we have started with an extensive needs assessment. We feel this is important as historically outsiders (national/regional governments or international donor agencies) have made decisions about the needs they perceive to exist. We feel that inequalities between countries and within countries need to be reduced to help improve the health and well-being of the poorest. 


\section{Acknowledgements}

The people of Nepal who participated in the research studies, community interventions and gave advice. The various students, whose projects contributed to improving the design of the intervention, Green Tara Trust UK for funding this challenging approach to maternity care and health promotion aimed at childbearing women.

\section{References}

1. WHO Ottawa Charter for Health Promotion, 1987. Geneva: World Health Organization.

2. Ministry of Health and Population (MOHP), New ERA and Macro International. Nepal Demographic and Health Survey 2006, 2007. Kathmandu, Nepal: Ministry of Health and Population, New ERA, and Macro International Inc.

3. Suvedi, B.K., Pradhan, A., Barnett, S., Puri, M., Chitrakar, S.R., Poudel, P. Sharma, S., Hulton, L. Nepal maternal Mortality and Morbidity Study 2008-2009: Summary of Preliminary Findings, 2009, Kathmandu, Nepal. Family Health Division, Department of Health Services, Ministry of Health, Government of Nepal [p:5].

4. UNDP. Nepal Millennium Development Goals: Progress Report, 2005. Available at [www.undp.org.np/publication/html/mdg2005/ mdg2005.php]. Accessed in Feb 2012.

5. HMGN. The Second Long Term Health Plan 1997-2017. Ministry of Health \& Population, Government of Nepal, 2009. Available at [http:/ /www.mohp.gov.np/english/publication/ second_long_term_health_plan_1997_2017.php]. Accessed in Feb 2012

6. WHO \& UNICEF. Antenatal Care in Developing Countries: Promises, Achievements and Missed Opportunities: An Analysis of Trends, Levels, and Differentials: 1990-2001, 2003. Geneva: WHO \& New York: UNICEF.

7. Jahn, A., Dar lang, M., Shah, U., Diesfeld, H.J. Maternity care in rural Nepal: a health service analysis. Trop Med Int Health, 2000, 5: p. 65765.

8. Pradhan, A., Aryal, R.H., Regmi, G., Ban, B., Govindasamy, P. Nepal Family Health Survey, 1996. Kathmandu: FHD/MoH Nepal

9. Simkhada, B., van Teijlingen E.R., Porter, M., Simkhada, P. Major problems and key issues in
Maternal Health in Nepal (Review), Kathmandu Univ M J, 2006, 4: 261-66.

10. Frank, A. G. The Development of Underdevelopment. Monthly Rev 1966, 18(4): 17-37.

11. Chambers, R. Ideas for Development. 2005, London: Earthscan (p:16,17).

12. FAO (Food \& Agriculture Organization of the United Nations) Communication: a key to human development, Natural Resources and Environment Department, FAO, Rome, 1994. Available at [http://www.fao.org/docrep/t1815e/ t1815e01.htm]. Accessed in Jan 2012.

13. Touwen, A. Handbook for Projects: Development Management \& Fundraising, Geneva, Switzerland: International Federation of University Women, 2001. Available at [http:// www.ifuw.org/training/pdf/projecthandbook.pdf]. Accessed in Feb 2012.

14. WHO SEARO. Nepal National Health System Profile - 2007, 2011, New Dehli: World Health Organization Regional Office for South-East Asia. Available at [http://www.searo.who.int/ LinkFiles/Nepal_Profile-Nepal.pdf]. Accessed in Dec 2011.

15. Simkhada, P., Baral, Y.R., van Teijlingen E. Health and Medical Research: A Bibliometric Review. Asia-Pac J Public Health, 2010, 22(4): 492-500. Available at [http://aph.sagepub.com/ content/22/4/492.full.pdf + html]. Accessed in Jan 2012.

16. Fujita, N., Matsui, M., Srey, S., Po, C.S., Uong, S., Koum, K. Antenatal care in the capital city of Cambodia: current situation and impact on obstetric outcome. J Obstet Gynaecol Res, 2005, 5 (2): 133-39.

17. Dickerson, T., Crookston, B., Simonson, S.E., Sheng, X., Samen, A., Nkoy, F. Pregnancy and village outreach Tibet: A descriptive report of a community- and home-based maternal-newborn outreach program in rural Nepal. J Perinatal Neonatal Nurs, 2010, 24(2): 113-25.

18. Central Bureau of Statistics. Statistical yearbook of Nepal 2001. 2001, Government of Nepal, National Planning Commission Secretariat.

19. Simkhada, P., van Teijlingen, E., Kadel, S., Stephens, J., Sharma, S., Sharma, M. Reliability of National Data Sets: Evidence from a Detailed 
Small Area Study in Rural Kathmandu Valley, Nepal. Asian J Epidemiol,2009, 2(2): 44-8.

20. Wade, A., Osrin, D., Shrestha, B.P., Sen, A., Morrison, J., Tumbahangphe, K.M., Manandhar, D.S., de Costello, A.M. Behaviour change in perinatal care practices among rural women exposed to a women's group intervention in Nepal [ISRCTN31137309] BMC Pregnancy Childbirth 2006, 6:20

21. Haines, A., Kuruvilla, S., Borchert, M. Bridging the implementation gap between knowledge and action for health. Bull World Health Org 2004, 82(10):724-731.

22. Manandhar, D.S., Osrin, D., Shrestha, B.P., Mesko, N., Morrison, J., Tumbahangphe, K.M., Tamang, S., Thapa, S., Shrestha, D., Thapa, B., et al. Effect of a participatory intervention with women's groups on birth outcomes in Nepal: cluster-randomised controlled trial. Lancet 2004, 364(9438):970-79.

23. Green, J. The role of theory in evidence-based health promotion practice. Health Educ Res 2000, 15(2): 125-29.

24. Hawe, P., Degeling, D., Hall, J. Evaluating Health Promotion: A Health Worker's Guide. MacLennan \& Petty, Sydney, 1990.

25. Campbell, M., Fitzpatrick, R., Haines, A., Kinmonth., A.L., Sandercock, P., Spiegelhalter, D., Tyrer, P. Framework for design and evaluation of complex interventions to improve health. Brit Med J, 2000; 321: 694.

26. Dhakal, S., Chapman, G., Simkhada, P., van Teijlingen E., Stephens J., Raja, A.E. Utilisation of postnatal care among rural women in Nepal, BMC Pregnancy Childbirth, 2007. 7(19). Available at [www.biomedcentral.com/content/ pdf/1471-2393-7-19.pdf]. Accessed in Mar 2012.
27. Dhakal, S., van Teijlingen, E., Raja, A.E., Dhakal, K.B. Skilled care at birth among rural women in Nepal: practice and challenges $\mathbf{J}$ Health Pop Nutr,2011, 29 (4): 371-78.

28. Dhakal, S., van Teijlingen, E.R., Stephens, J., Dhakal, K.B., Simkhada, P., Raja, E.A., Chapman, N.G. Antenatal care among women in rural Nepal: A community-based study. Online J Rural Nurs Health Care, 2011. 11(2): 76-87. Available at [http://rnojournal.binghamton.edu/ index.php/RNO/article/view/20]. Accessed in Feb 2012.

29. Simkhada, B., van Teijlingen E., Porter, M., Simkhada, P. Factors affecting the utilisation of antenatal care in developing countries: a systematic review of the literature. J Advanc Nurs, 2008, 61(3): 244-60.

30. Fitzpatrick P. Young People's Sexual Health Needs Assessment in Nepal Unpublished MSc thesis, Aberdeen, University of Aberdeen, 2006.

31. Simkhada, B., Porter, M., van Teijlingen, E. The role of mothers-in-law in antenatal care decisionmaking in Nepal: A qualitative study. BMC Pregnancy Childbirth, 2010, 10(34). Available at www.biomedcentral.com/content/pdf/14712393-10-34.pdf . Accessed in Jan 2012.

32. Morrison, J Tamang, S., Mesko, N., Osrin, D., Shrestha, B., Manandhar, M., Manandhar, D., Standing, H., Costello, A. Nepal: Women's health groups to improve perinatal care in rural Nepal BMC Pregnancy Childbirth 2005, 5:6. Available at http://www.wcf-uk.org/attachments/article/ 240/JMorrisonWG.pdf

33. Patton, M. Utilization-focused Evaluation Eval Educ HumServ. 2002, 49: 425-38. 